\title{
Building a Culture of Prevention: Tasks for Multi-Taskers
}

\author{
Maria Rosaria Galanti ${ }^{1}$ \\ Published online: 3 September 2020 \\ (C) Society for Prevention Research 2020
}

\begin{abstract}
Building a culture of prevention presents many challenges, all of which originate from and refer back to both strengths and weaknesses of this effort. In this invited commentary, I provide an overview of these challenges and remaining open questions extracted from the original contribution enclosed in the special issue. Crucial questions that need to be addressed are the use of formal models of a "culture of prevention"; how the interplay of local values, alliances, and co-creational processes can be reflected in other experiences; and evaluation of the culture change itself.
\end{abstract}

No time is more suitable than the present one-facing the universal menace of the COVID-19 pandemic - to reflect on the alliance of these two terms: "culture" and "prevention," if not for other reasons to preserve the idea of pursuing sustainable health goals for the whole planet.

The excellent issue of Prevention Science guest-edited by Petras and collaborators on this theme offers valuable suggestions to conceptualize this alliance, at the same time presenting at least as many challenges and questions. These challenges are expected and desirable. "Cultures" do not raise (and do not fall) in weeks or months, not even years. Therefore, I focus more on expanding on the problematic and provoking sides of this complicated matter, rather than on the merits of the contributions of the specific papers.

\section{Formal Models of a Culture of Prevention: Why Do We Need Them?}

The contributions in this issue refer to different aspects of formalization of the concept "culture of prevention" in terms of its theoretical antecedents and constituents. These efforts are laudable, most of the time leading to the identification of similar or identical ingredients" (perhaps not surprising since the contributors may share similar academic and network environments). Examples of these ingredients are the translation in the current practice of effective interventions (Heikkilä et al. 2020) and envisioning multi-level (system) changes and

Maria Rosaria Galanti

rosaria.galanti@ki.se

1 Department of Global Public Health, Karolinska Institutet, Solna, Sweden partnerships (Bollmann et al. 2020; Exner-Cortens et al. 2019; Murphy et al. 2018; Sentell et al. 2018). These efforts are courageous, because they use "cultural models" as a proactive and conscious process, far from the historically more common inductive process of deriving cultural models to classify and interpret facts and observations. However, I feel the urgency of sharing thoughts on a more fundamental question: why do we need formal models of something so elusive as "culture-shaping"? How are we going to use these formal models? The paper by Bollmann et al. (2020) contains valuable hints to address these questions. Perhaps, we should explicitly endorse the challenge that cultural models of prevention should be used to make previsions, not to explain what just happened or to constrain specific actions in a definite frame. As such, they should be theoretically robust but also dynamic and timely. This point is intimately laced to the need for evaluation, which I will address below.

\section{Contextuality vs. Exportability of Preventive Models}

This issue forms the leading track of the contribution by Mauricio et al. (2018) but is also directly or indirectly taken up in the articles authored by Parra-Cardona et al. (2018) and by Rowland et al. (2019). If the primary nurture of culture rests in a community's shared values that operate beyond individual differences (Abdullah and Brown 2011), this means that there would be virtually as many "prevention cultures" as there are communities (however, these are defined). An extreme consequence of this appraisal would be that any cultural model is inherently local, and the very same idea of "exporting" it to other contexts should be discouraged. 
To solve this dilemma in prevention (programs' effectiveness calls for dissemination, but context specificity of effects discourage it) efforts have been put in the latest two decades in the "cultural adaptation" of specific programs tackling behavioral outcomes when evidence of effectiveness was established in the original settings. This approach has yielded mixed results in formal evaluations (Skärstrand et al. 2014; Ghaderi et al. 2018; Cainelli de Oliveira Prado et al. 2016; Tingstrom et al. 2006).

No program can be adapted in its fundamentals, i.e., the assumptions stemming from original communities' shared values. If so, then we should acknowledge that a "re-creation" process rather than an adaptation is at stake. These communityshared values are so influential in determining the uptake, and the effects of a particular action that claims of similarity of contexts based on the prevalence of behaviors or health care infrastructure are not enough. To clarify, I am not dismissing the transfer of successful experiences. What I am proposing is a comprehensive approach to the exportability of programs, first of all, distinguishing methods from prototypes (Hawkins et al. 2017) and (second, but most important) resting on more complex re-creational and co-creational processes (see also point 3 below). This approach may ultimately result in new prototypes, at times quite distant from the original ones. While the initial prototype may continue to serve as an inspirational source, the new prototypes will be the ones with a likely impact on the communities' health.

\section{Inter-sectorial Systemic Alliances and the Process of Co-production}

This lesson has been universally taken. No prevention culture can foster viable programs or even declare to exist without cross-system thinking (Murphy et al. 2018). This is particularly important in contexts such as low- and middle-income countries (LMIC) (Parra-Cardona et al. 2018) where the local shared values around health, the understanding of health determinants, the perceived needs of change, and the role of decision-makers in promoting these changes can be less homogeneous than in high-income countries and diversely nurtured by familial, communize, and macro-level responses.

In cross-system thinking, we learn to recognize "systems" not only as a distal institutional level (health care, educational system, etc.) but also at the micro-level (individuals, networks). Observed and ideal networks are thereby designed on both a horizontal level (e.g., between individuals, families, or institutional bodies) and a vertical level (e.g., between citizens and health care systems or school systems) (Hawe et al. 2009).

Central to cross-system synergies is the concept of "coproduction" (i.e., the process through which inputs from sources that are not in the same organization are incorporated in the production of goods or services) (Ostrom 1996). In health promotion or prevention, this concept has gained enormous momentum in the latest 5 to 6 years. We need to admit that our understanding and our practices of co-production are fundamentally limited and often do not go beyond declarations of intent or exemplary cases of partnerships. However, the recognition of the added value of knowledge generated at any point in the production because of new social interactions is commonly accepted as a core component of co-production (Filipe et al. 2017).

Along this line, by incorporating co-production in the "culture of prevention" at the institutional level, we face an unprecedented endeavor, as we (if anyone) need to go further. What is to be co-produced: models, prototypes, knowledge, regulations? Through which cycle? How do decision and control functions intervene in these cycles? Which knowledge should be used (and which should be discarded)? The contribution of Murphy et al. (2018) offers a very inspiring example of advancing the field in school-based prevention.

\section{Targets' Complexity and the Limits of Governance}

The targets of prevention are typically complex and increasingly so, encompassing not only and perhaps no longer primarily individuals' behaviors or disease occurrence. By recognizing that many individual risk factors or undesirable events have common determinants (e.g., substance use and mental ill-health), upstream structural approaches are making their way into the storehouse of programs for prevention, health promotion, and reduction of inequality in health (Mackenbach et al. 2008). Because of this upward shift, prevention scientists are more often called to address social processes. These are typical of much higher levels of complexity as compared with individuals' smoking behavior or hazardous drinking. These complex processes may include positive parenting, reduction of wastes, effective education, health literacy, women empowerment, and re-creational life of youths, just to cite some.

This involvement is very relevant to the goal of building a culture of prevention. First, in the obvious sense, these intricate processes are so inherently connected with communities' functions (and dysfunctions) that they cannot be changed without general cultural changes, i.e., changes in how individuals and communities conceive and commit to desirable and sustainable levels of quality of life. But building a culture of prevention around these complex processes also conveys the complementary obligation of acknowledging theoretical and practical limits in the amount of governance and "turbulence" that individuals and communities may be able to accept to preserve their own identities through changes. The coproductive approach should be regarded as one guarantee in this pathway. 


\section{The Double Face of Evaluation}

My last point concerns evaluation. Again, all contributions in this issue of Prevention Science highlight the need for a sound evaluation at some point in the process of creating a culture of prevention. However, I discern two distinct ways with which this need is felt and addressed. On the one side, evaluation is advocated as a necessary component of a sustainable culture of prevention (Heikkilä et al. 2020), a practice that transforms the traditional (and in some contexts still dominant) culture of "no evidence of harm" (how often assessed, by the way?) into a progressive culture of "evidence of benefits" and of "benefits for investments." This task is becoming increasingly demanding, along with the increasing complexity of prevention targets, and requires pioneer methodologic approaches involving triangulation of questions (Munafò and Davey Smith 2018) and cascades of interconnected outcome measures. But there is another discourse on evaluation trickling through the contributions in this issue of Prevention Science, namely, the need to evaluate the progress in "culture building." When do we know that culture has changed? And how do we know that the change is going to stay? What does the balance between rupture and continuity look like? There is no better time than the present one to attend to these questions when collective responses to the COVID-19 pandemic are modeling our "health culture" beyond any expectation.

\section{Compliance with Ethical Standards}

Conflict of Interest The authors declare that they have no conflict of interest.

Ethical Approval All procedures performed in studies involving human participants were in accordance with the ethical standards of the institutional and/or national research committee and with the 1964 Helsinki Declaration and its later amendments or comparable ethical standards.

Informed Consent Informed consent was obtained from all individual participants included in the study.

\section{References}

Abdullah, T., \& Brown, T. L. (2011). Mental illness stigma and ethnocultural beliefs, values, and norms: An integrative review. Clinical Psychology Review, 31, 934-948.

Bollmann, U., Lee, Y. J., Kohstall, T., Hessenmöller, A. M., Bochmann, C., \& Paridon, H. (2020). International leading indicators for a culture of prevention - How to measure the unmeasurable?. Manuscript submitted for publication.

Cainelli de Oliveira Prado, M., Schneider, D. R., Sañudo, A., Pereira, A. P. D., Horr, J. F., \& Sanchez, Z. M. (2016). Transcultural adaptation of questionnaire to evaluate drug use among students: The use of the
EU-Dap European questionnaire in Brazil. Substance Use \& Misuse, 51, 449-458.

Exner-Cortens, D., Wells, L., Lee, L., et al. (2019). Building a culture of intimate partner violence prevention in Alberta, Canada Through the Promotion of Healthy Youth Relationships. Prevention Science. https://doi.org/10.1007/s11121-019-01011-7.

Filipe, A., Renedo, A., \& Marston, C. (2017). The co-production of what? Knowledge, values, and social relations in health care. PLoS Biology, 15.

Ghaderi, A., Kadesjö, C., Björnsdotter, A., \& Enebrink, P. (2018). Randomized effectiveness trial of the family check-up versus internet-delivered parent training (iComet) for families of children with conduct problems. Scientific Reports, 8, 1-15.

Hawe, P., Shiell, A., \& Riley, T. (2009). Theorising interventions as events in systems. American Journal of Community Psychology, 43, 267-276.

Hawkins, J., Madden, K., Fletcher, A., Midgley, L., Grant, A., Cox, G., et al. (2017). Development of a framework for the co-production and prototyping of public health interventions. BMC Public Health, 17, 689

Heikkilä, H., Maalouf, W., \& Campello, G. (2020). The United Nations Office on Drugs and Crime's efforts to strengthen a culture of prevention in low- and middle-income countries. Prevention Science. https://doi.org/10.1007/s11121-020-01088-5.

Mackenbach, J. P., Stirbu, I., Roskam, A. J. R., Schaap, M. M., Menvielle, G., Leinsalu, M., \& Kunst, A. E. (2008). Socioeconomic inequalities in health in 22 European countries. New England Journal of Medicine, 358, 2468-2481.

Mauricio, A. M., Rudo-Stern, J., Dishion, T. J., et al. (2018). Facilitators and barriers in cross-country transport of evidence-based preventive interventions: A case study using the family check-up. Prevention Science. https://doi.org/10.1007/s11121-018-0929-y.

Munafò, M. R., \& Davey Smith, G. (2018). Repeating experiments is not enough. Nature, 553, 399-401.

Murphy, S., Littlecott, H., Hewitt, G., et al. (2018). A transdisciplinary complex adaptive systems (T-CAS) approach to developing a national school-based culture of prevention for health improvement: The School Health Research Network (SHRN) in Wales. Prevention Science. https://doi.org/10.1007/s11121-018-0969-3.

Ostrom, E. (1996). Crossing the great divide: Co-production, synergy, and development. World Development, 24(6), 1073-1087.

Parra-Cardona, R., Leijten, P., Lachman, J. M., et al. (2018). Strengthening a culture of prevention in low- and middle-income countries: Balancing scientific expectations and contextual realities. Prevention Science. https://doi.org/10.1007/s11121-018-0935-0.

Rowland, B., Jonkman, H., Steketee, M., et al. (2019). A cross-national comparison of the development of adolescent problem behavior: A 1-year longitudinal study in India, the Netherlands, the USA, and Australia. Prevention Science. https://doi.org/10.1007/s11121019-01007-3.

Sentell, T. L., Ylli, A., Pirkle, C. M., et al. (2018). Promoting a culture of prevention in Albania: The "Si je?" Program. Prevention Science. https://doi.org/10.1007/s11121-018-0967-5.

Skärstrand, E., Sundell, K., \& Andréasson, S. (2014). Evaluation of a Swedish version of the strengthening families programme. The European Journal of Public Health, 24, 578-584.

Tingstrom, D. H., Sterling-Turner, H. E., \& Wilczynski, S. M. (2006). The good behavior game: 1969-2002. Behavior Modification, 30, $225-253.15$

Publisher's Note Springer Nature remains neutral with regard to jurisdictional claims in published maps and institutional affiliations. 